\title{
Comparative Study: The Adsorption Disparity for Tetracycline and Cefradine on Cornstalk Biochar
}

\author{
Khan Ahmad Ali*, Guoting Li**† and Wenchuan Wang* \\ *School of Water Conservancy, North China University of Water Resources and Electric Power, Zhengzhou 450011, \\ China \\ **S School of Environmental and Municipal Engineering, North China University of Water Resources and Electric Power, \\ Zhengzhou 450011, China \\ $†$ Corresponding author: Guoting Li; lipsonny@126.com
}

Nat. Env. \& Poll. Tech.

Website: www.neptjournal.com

Received: $20-12-2019$

Revised: 03-01-2020

Accepted: 28-03-2020

Key Words:

Adsorption

Cornstalk

biochar

Cefradine

Tetracycline

\begin{abstract}
The study gives the elimination of two kinds of antibiotics, tetracycline (TC) and cefradine (CF) by adsorption process, on the biochar derived from cornstalk. Dense, multifaceted and thick fragments of raw cornstalk almost all vanished at a pyrolytic temperature above $400^{\circ} \mathrm{C}$. The carbon content increased from $60.48 \%$ of the raw cornstalk to $75.5 \%$ of the cornstalk biochar pyrolyzed at $600^{\circ} \mathrm{C}$ (BC600), while the oxygen content decreased from $17.31 \%$ to $6.94 \%$. The uptake of each TC and CF on the cornstalk biochar was highly $\mathrm{pH}$-dependent. The maximum adsorption capacities of TC and CF at $298 \mathrm{~K}$ calculated from the Langmuir mannequin have been 28.0 and $38.0 \mathrm{mg} / \mathrm{g}$, respectively. The Columbic interaction and $\pi-\pi$ electron-donor-acceptor interaction between cornstalk biochar and CF/ TC molecules played the main role. The experimental records were well outfitted by way of the ability of the pseudo-second-order kinetics model, indicating a possible chemisorption process to some extent. Isotherm result implied that both adsorption and partitioning contributed to the uptake of TC and CF onto BC600.
\end{abstract}

\section{INTRODUCTION}

For wastewater treatment, adsorption technology has become the most familiar, attractive and effective. For, adsorption technology, without production of any other toxic byproducts or intermediates pollutants, contaminants could be attached on the adsorptive materials surface area and can be easily removed or separated from treated water by filtration or centrifugation (Ali et al. 2012, Qu 2008). As such, many adsorbents have been found and synthesized for eliminating inorganic pollutants (e.g. heavy metals, arsenic and fluoride etc.) and organic pollutants (e.g. antibiotics, dyes, PPCP's, pesticides, etc.) from wastewater. Carbon-containing adsorbents are usually the most useful for eliminating organic pollutants due to their large surface area, high affinity towards organic compounds, and easy to reuse and regeneration. For wastewater treatment, low-cost and efficient biochars, which are mostly derived from agricultural wastes or natural biomass, have attracted increasing preference. The preparation of biochar offers the chance to turn bioenergy into a carbon-negative industry, with carbon sequestration and gas capture, which are expected to be a carbon-neutral energy source (Lehmann 2007, Lee et al. 2010). Also, biochar has proved an important role in climate change extenuation, energy production, waste management, soil improvement and environmental management (Ahmad et al. 2014, Zhou et al. 2015, Ge \& Qu 2003). For adsorptive elimination of inorganic/ organic pollutants from wastewater and soil, the biochars are particularly considered as an environment friendly adsorbent (Rokhina et al. 2013, Kim et al. 2005, Polubesova et al. 2006). Adsorption capability of different pollutants depends on their chemical and physical properties, factors affecting are pyrolysis conditions, pyrolysis technologies and feedstock even raw biochar has the low capability to remove pollutants from wastewater (Figueroa et al. 2004). The use of agricultural by-products or wastes for environmental protection has received marvellous consideration as they are low-cost, abundant in source and renewable (Chen et al. 2018, Peng et al. 2017, Wang et al. 2017). There was 7.18 hundred million tons of crop straw in 2015 and corn stalks were account for $34.2 \%$ by Statistical data of Chinese Academy of Agricultural Sciences (Da-li et al. 2018), which shows an enormous amount of cornstalk biomass. Biochar formed by combusting corn stalks (composed of lignin, cellulose, and hemicelluloses) under limited oxygen environments encompasses high specific surface area, stable structures, and a large amount of surface sites, which can be utilized to eliminate ecological contaminants (Yang et al. 2017a, 
Yang et al. 2017b, Yang et al. 2017c). Direct application of raw cornstalk for the adsorptive elimination of organic pollutants is lack of practical application potential since the likely organic leaching from cornstalk results secondary pollution problem. As unique characteristics of cornstalk, the biochar synthesized from cornstalk is considered to have a new porous microstructure and large surface area, resulting in improvement of the adsorptive elimination of pollutants.

Due to not easily degradable, the antibiotics can cause a lot of environmental problems in marine environments, the antibiotics resistance of bacteria has been increased due to remaining antibiotics, aquatic organisms face bioaccumulation and biomagnification by the impact of residue antibiotics (Bai et al. 2014,four quinolones, three tetracyclines and two macrolides in water, sediment, and biota samples from the Liao River Basin, China were investigated in the present study. The samples were collected in May 2012, and laboratory analyses revealed that antibiotics were widely distributed in the Liao River Basin. Macrolides made up the majority of antibiotics in the water ranging from not detected (ND Gao et al. 2012, distribution and bioaccumulation of 22 antibiotics, including eight fluoroquinolones (FQs Kim et al. 2014)the freshwater crustacean Daphnia magna. D. magna was exposed to algal food (Pseudokirchneriella subcapitata. Tetracycline (TC) and cefradine (CF) have different functional groups but have similar molecular weight. To find out some important results and comparing the adsorption capacity of TC and CF will be motivating. In this study, cornstalk biochar was synthesized through a simple and cost-effective pyrolysis method, and innovatively applied for adsorptive elimination of the two usual emerging PPCPs. To determine and compare the adsorption capacity of TC and CF on cornstalk biochar a series of batch adsorption experiments were directed and adsorption mechanism was discussed as well.

\section{MATERIALS AND METHODS}

\section{Materials}

Tetracycline hydrochloride (TC, molecular weight 444) was purchased from Solarbio Lifesciences Company (Beijing, China), and Cefradine (CF, A.R.) from Tianjin Fengfan Chemical Reagent Company (Tianjin Province, China). All the chemicals used were of analytical grade. Deionized (DI) water was used to prepare all the solutions.

\section{Preparation of Cornstalk Biochar}

Raw cornstalk was collected from the farmland of Zhengzhou (Henan Province). After washing, drying, crushing and sieving (using a 40 mesh sieve) the cornstalk biomass was put into a ceramic pot with pressed state and enclosed with a fitting lid. The cornstalk was pyrolyzed at different temperatures for $3 \mathrm{~h}$ under an oxygen-limited condition. After it was treated with $\mathrm{HCl}$ for 12 hours and then after filtration, the residues were rinsed with DI water to neutral $\mathrm{pH}$ and dried in an oven at $80^{\circ} \mathrm{C}$ overnight. Prepared biochar was preserved in a desiccator for further use. The cornstalk biochars pyrolyzed at $400^{\circ} \mathrm{C}$ and $600^{\circ} \mathrm{C}$ were designated as $\mathrm{BC} 400$ and $\mathrm{BC} 600$, respectively.

\section{Characterization}

By using Philips Quanta-2000 scanning electron microscope (SEM) combined with an energy dispersive X-ray (EDX) spectrometer, the morphology of the raw cornstalk and cornstalk biochars pyrolyzed at different temperatures were recorded. To analyse the zeta potential of the cornstalk biochar pyrolyzed at $600^{\circ} \mathrm{C}$, a zeta potential analyser (Zetasizer 2000, Malvern Co., UK) was used. Nicolet NEXUS 470 FTIR spectrophotometer was used for recording spectra of Fourier transform infrared spectroscopy (FTIR) in a range of 400 to $4000 \mathrm{~cm}^{-1}$. By using surface area and pore-size analyser (NOVA 2200 e, USA) and Brunauer, Emmett and Teller (BET) method the specific surface area of biochars was measured.

\section{Batch Adsorption Experiment}

A fresh stock solution of TC and CF was prepared by dissolving $(500 \mathrm{mg} / \mathrm{L})$ in DI water and stored in a refrigerator at $277 \mathrm{~K}$. For experimental work the stock solution was used for the preparation of required concentration solutions of $\mathrm{CF}$ and CF by diluting with DI water of each. In experimental work to find out the adsorption isotherms and $\mathrm{pH}$ effect, the $20.0 \mathrm{mg} / \mathrm{L}$ concentration of TC or CF was used with the 0.4 $\mathrm{g} / \mathrm{L}$ dose of cornstalk biochar. At a constant temperature of $298 \mathrm{~K}$ shaking at $145 \mathrm{rpm}$ for $24 \mathrm{~h}$, samples were collected and filtered through a $0.45 \mu \mathrm{m}$ syringe membrane filter before concentration measurement. The $\mathrm{pH}$ of the solution was adjusted by using diluted $\mathrm{HNO}_{3}$ or $\mathrm{NaOH}$ at neutral $\mathrm{pH}$ except during the $\mathrm{pH}$ effect study itself. For the kinetics study, $400 \mathrm{mg}$ of cornstalk biochar was added into $1000 \mathrm{~mL}$ of $20.0 \mathrm{mg} / \mathrm{L}$ TC or CF solution.

\section{Concentration Analyses}

A UVmini-1240 spectrophotometer (Shimadzu, Japan) was used to analyse the concentrations of TC and CF at the wavelength of maximum absorption at 360 and $264 \mathrm{~nm}$, respectively (Gao et al. 2012, distribution and bioaccumulation of 22 antibiotics, including eight fluoroquinolones (FQs Kim et al. 2014)the freshwater crustacean Daphnia magna. D. magna was exposed to algal food (Pseudokirchneriella subcapitata. The adsorption capacities were calculated as follows:

$$
q_{e}=\left(C_{o}-C_{e}\right) \mathrm{V} / \mathrm{W}
$$




$$
q_{t}=\left(C_{o}-C_{t}\right) \mathrm{V} / \mathrm{W}
$$

Where, $q_{e}$ and $q_{t}(\mathrm{mg} / \mathrm{g})$ are the adsorption capacities at equilibrium and time $t(\mathrm{~min}) ; C(\mathrm{mg} / \mathrm{L})$ is the initial concentration of TC or CF in solution, while $C_{e}$ and $C_{t}(\mathrm{mg} / \mathrm{L})$ are the concentrations of TC or CF at equilibrium and $t(\mathrm{~min})$, respectively; $\mathrm{V}(\mathrm{L})$ is the volume of solution, and $\mathrm{W}(\mathrm{g})$ is the mass of the cornstalk biochar used.

\section{RESULTS AND DISCUSSION}

\section{Characterization of Cornstalk and Cornstalk Biochar}

SEM and EDX: Fig.1 shows the SEM images of the raw cornstalk and the cornstalk biochars pyrolyzed at $400^{\circ} \mathrm{C}$ (BC400) and $600^{\circ} \mathrm{C}$ (BC600). From Fig.1(a,b), it can be seen that the cornstalk mainly consisted of dense and multifaceted fragments. After pyrolysis at $400^{\circ} \mathrm{C}$, thin flecks outweighed and the thick fragments nearly all vanished confirming that pyrolysis slashed the natural films of the cornstalk compared with the raw cornstalk. The fragments of BC400 and BC600 became smaller as showed in Fig.1(c,d), so the increase in pyrolytic temperature produced a more condensed structure of cornstalk biochar. By EDX the contents of $\mathrm{C}, \mathrm{N}$ and $\mathrm{O}$, molar ratios of $\mathrm{O} / \mathrm{N},(\mathrm{O}+\mathrm{N}) / \mathrm{C}$ and wt. \% values in the raw cornstalk and cornstalk biochar are represented in Fig. 2. Cornstalk and cornstalk biochar pyrolyzed at $400^{\circ} \mathrm{C}$ and $600^{\circ} \mathrm{C}$ were all carbon-rich, with $\mathrm{C}$ (carbon) contents increasing from $60.5 \%$ of the cornstalk

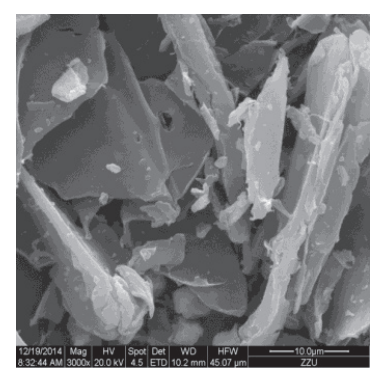

(a)

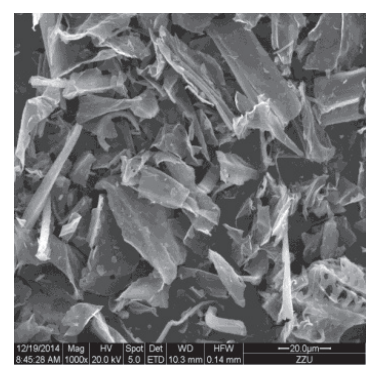

(c) to $75.5 \%$ of the cornstalk biochar pyrolyzed at $600^{\circ} \mathrm{C}$. The carbon content of cornstalk biochar (75.5\%) in this research were especially close to that of cornstalk biochar treated by pyrolysis in an $\mathrm{N}_{2}$ environment at $600^{\circ} \mathrm{C}$ as shown by elemental analysis (Yao et al. 2014). Also, the $\mathrm{N}$ content increased gradually from $3.1 \%$ of the raw cornstalk to $6.0 \%$ of the cornstalk biochar BC600. The increased N content was also observed by other researchers (Sun et al. 2014, Avilez 2012, Al-Wabel et al. 2013)ash content, pH, electrical conductivity, basic functional groups, carbon stability, and total content of $\mathrm{C}, \mathrm{N}, \mathrm{P}, \mathrm{K}, \mathrm{Ca}$, and $\mathrm{Mg}$ increased while biochar yield, total content of $\mathrm{O}, \mathrm{H}$ and $\mathrm{S}$, unstable form of organic $\mathrm{C}$ and acidic functional groups decreased. The ratios of $\mathrm{O} / \mathrm{C}, \mathrm{H} / \mathrm{C},(\mathrm{O} .+. \mathrm{N}$ and in specific, the $\mathrm{O}$ contents dropped from $17.3 \%$ of the raw cornstalk to $6.9 \%$ of the cornstalk biochar.

Before and after pyrolysis treatment the relative molar ratios of $\mathrm{O} / \mathrm{C}$ and $(\mathrm{O}+\mathrm{N}) / \mathrm{C}$ could imitate the change to some extent of surface hydrophilicity and functional groups of the raw cornstalk and biochars. The molar ratios of $\mathrm{O} / \mathrm{N}$ and $(\mathrm{O}+\mathrm{N}) / \mathrm{C}$ decreased from $21.5 \%$ to $6.9 \%$ and from $25.9 \%$ to $13.7 \%$, respectively on BC600. The decrease of $(\mathrm{O}+\mathrm{N}) / \mathrm{C}$ molar ratio showed the loss of the surface polar functional groups while the fall of $\mathrm{O} / \mathrm{N}$ molar ratio showed that the biochar surface became less hydrophilic (Chen \& Chen 2009, Chun et al. 2004, Cornelissen \& Gustafsson 2005). Above discussion signifies that biochar derived from cornstalk could have a certain amount of polar functional groups on the

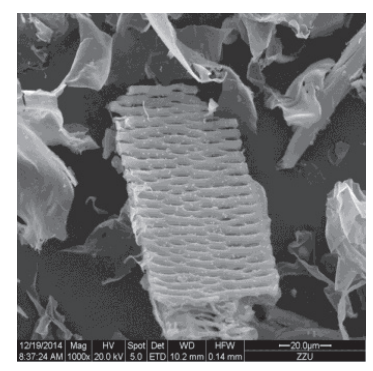

(b)

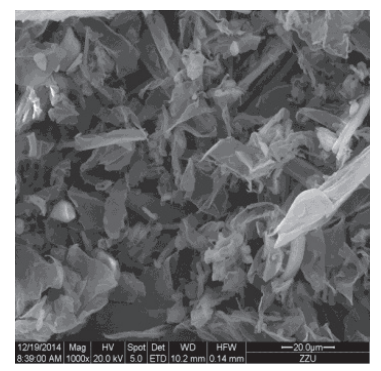

(d)

Fig. 1: Scanning electron microscopy images of the raw cornstalk (a, b) and cornstalk biochars BC400 (c) and BC600 (d). 


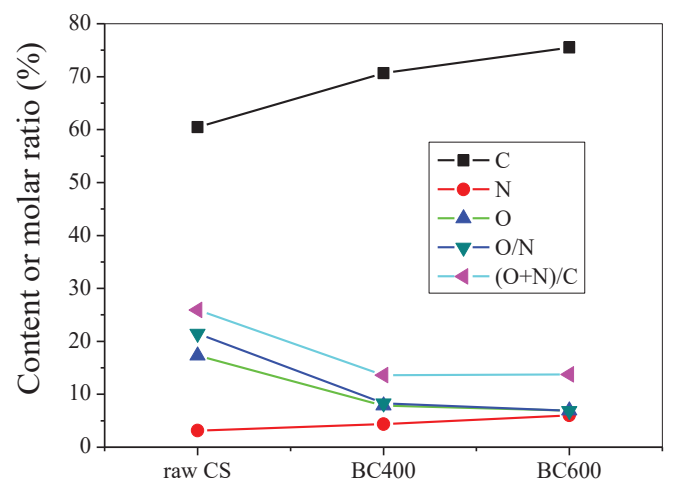

Fig. 2: Changes in element contents (wt \%) of $\mathrm{C}, \mathrm{N}, \mathrm{O}$ and the molar ratios $(\%)$ of $\mathrm{O} / \mathrm{N}$ and $(\mathrm{O}+\mathrm{N}) / \mathrm{C}$ in the raw cornstalk, and cornstalk biochars BC400 and BC600.

surface and facilitate the diffusion and adsorption of polar organic pollutants on the biochar surface.

BET surface area: Specific surface area and pore structure characteristics of the biochar were measured by BET method as illustrated in Fig. 3. The surface area of cornstalk biochar was $315.8 \mathrm{~m}^{2} / \mathrm{g}$, and pore size $5.58 \mathrm{~nm}$, respectively, while the raw cornstalk surface area was $1.3 \mathrm{~m}^{2} / \mathrm{g}$, and pore size 1.98 $\mathrm{nm}$. The results of the analysis suggested that the cornstalk biochar contained high surface area and total pore volume compared with other sludge-based activated carbon materials (Li et al. 2011)specific surface area, zeta potential, scanning electron microscope and X-ray diffraction. Adsorption experiments were conducted as function of particle size, SAC dosage, $\mathrm{pH}$, salt concentration, contact time and initial concentration. Desorption of dyes on SAC was studied in deionized water with different $\mathrm{pH}$ values and the dye-exhausted carbon was regenerated by thermal treatment. The results showed that the equilibrium adsorption data were well represented by the Langmuir isotherm equation. The maximum adsorption capacity (263.16. mg/g for MB and 34.36. $\mathrm{mg} / \mathrm{g}$ for RR 24. It was reported that specific surface area of activated carbon prepared from paper mill sewage sludge by carbonization at low temperature was about $130-140 \mathrm{~m}^{2} / \mathrm{g}$
(Monsalvo et al. 2011), while BET surface areas of activated carbons prepared from dried sewage sludge using $\mathrm{CO}_{2}$, air and $\mathrm{KOH}$ as activating agents were below $100 \mathrm{~m}^{2} / \mathrm{g}$. Even though, the biochar usually has a lower specific surface area than commercial activated carbons, which typically have a specific surface area of about 400 1,500 $\mathrm{m}^{2} / \mathrm{g}$. The biochar was classified as mesoporous material with an average pore size falling in the range of 2-50 $\mathrm{nm}$ (Chen et al. 2011). These results suggested that biochar with higher surface area and more pore volume may be used as potential adsorbent.

FTIR: The FTIR spectra of cornstalk and cornstalk biochar samples prepared at different pyrolytic temperatures are shown in Fig. 4. First, the strong band at $3,420 \mathrm{~cm}^{-1}$ represents the stretching vibration of the hydroxyl group $(\mathrm{OH})$, which became weaker with increasing pyrolytic temperature. This indicated the significant loss of moisture and water of hydration, as a consequence of pyrolysis. Secondly, the bands at $2,903 \mathrm{~cm}^{-1}$ (aliphatic C-H stretching), at $1,035 \mathrm{~cm}^{-1}$ and $1,105 \mathrm{~cm}^{-1}$ (C-O-C), at $1,247 \mathrm{~cm}^{-1}\left(\mathrm{CH}_{2}\right)$ and $(\mathrm{C}-\mathrm{O}$ in the acetyl group) almost disappeared after heating to $400^{\circ} \mathrm{C}$ simultaneously, while the intensity at $1,607 \mathrm{~cm}^{-1}$ (aromatic $\mathrm{C}=\mathrm{C}$ and $\mathrm{C}=\mathrm{O}$ ), faded (Chen \& Chen 2009, Zhu et al. 2014, Luo et al. 2014). The FTIR data study behaviour coordinat-

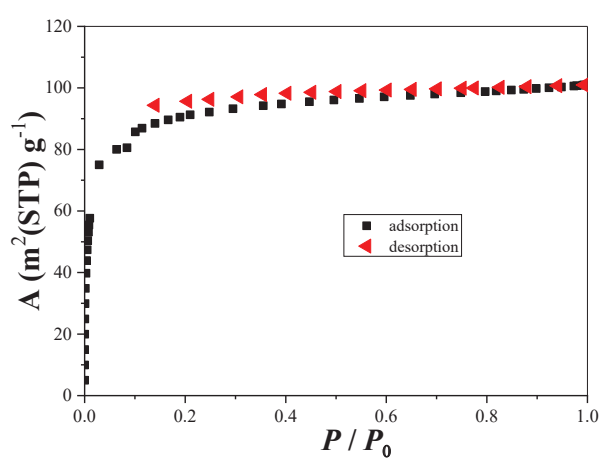

Fig. 3: BET surface areas and average pore sizes of the raw cornstalk, cornstalk biochars BC400 and BC600. 


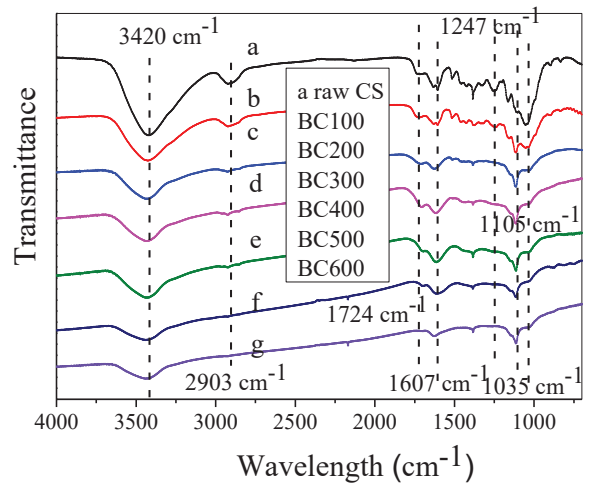

Fig. 4: FTIR spectra of the raw cornstalk, and cornstalk biochars samples prepared under pyrolysis temperatures from $100^{\circ} \mathrm{C}$ to $600^{\circ} \mathrm{C}$.

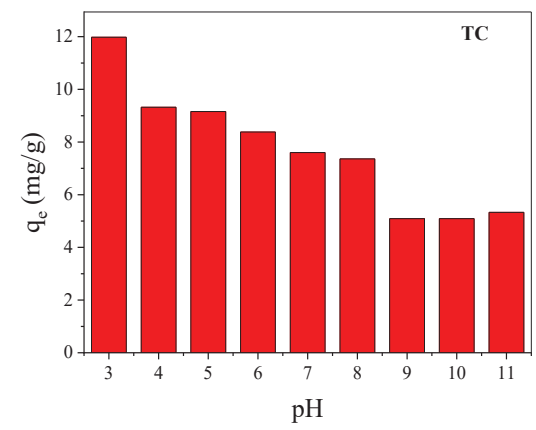

(a)

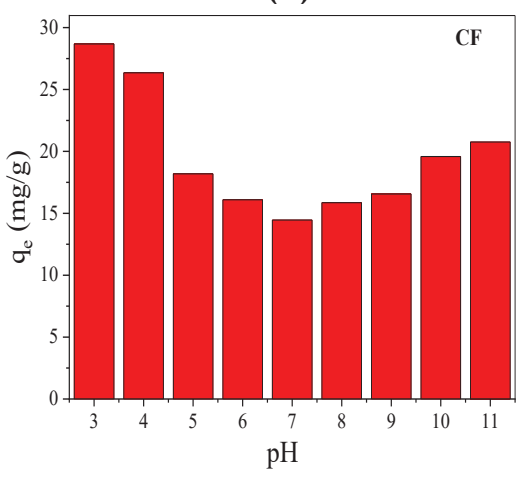

(b)

Fig. 5: Effect of solution pH on the adsorption of TC (a) and CF (b) by using BC600.

ed with EDX observations. Finally, the band at $1,700 \mathrm{~cm}^{-1}$ $(\mathrm{C}=\mathrm{O})$ eliminated, which is in accordance with other studies, as the elimination of the band at $1,700 \mathrm{~cm}^{-1}$ was observed by other researchers (Zhu et al. 2014, Luo et al. 2014, Carvalho et al. 2011). This implied that the content of $\mathrm{C}=\mathrm{N}$ functional groups among oxygen-containing functional groups increased while the concentration of other oxygen-containing functional groups diminished concurrently.

\section{Effect of Solution pH on the Adsorption of TC and CF}

To eliminate the TC and CF from wastewater, cornstalk biochar BC600 was preferred based on the stability and surface properties. The uptake of CF was higher than that of TC at a low adsorbate concentration, and the removal of both TC and CF decreased gradually with increasing solution $\mathrm{pH}$ (Song et al. 2019). Fig.5(a, b) shows the effect of 
solution $\mathrm{pH}$ in the $\mathrm{pH}$ range of 3.0 to 11.0 . It is found that the removal efficiency of TC and CF from wastewater was highly $\mathrm{pH}$-dependent and was higher in acidic condition as compared to alkaline condition, which was the indication of H-bond formation during adsorption. The experimental results show that the optimum adsorption for both TC and $\mathrm{CF}$ was achieved at $\mathrm{pH} 3.0$ with the adsorption capacities of 12.0 and $28.7 \mathrm{mg} / \mathrm{g}$, respectively which decreased with the increase in solution $\mathrm{pH}$. The adsorption of TC was less than that of $\mathrm{CF}$ in the testing $\mathrm{pH}$ range. Commonly, the surface charge of the biochar should be significantly pretentious by solution $\mathrm{pH}$ and a more negatively-charged biochar surface is hypothetically promising for the adsorption of positively charged contaminants due to Columbic attraction (Ahmadzadeh et al. 2015). Fig. 6 represents the Zeta potential of the biochar BC600 as a function of solution $\mathrm{pH}$. With the increasing solution $\mathrm{pH}$, the surface charge of BC600 in the $\mathrm{pH}$ range of 3.0 10.0 turned to be more negative. Though TC and $\mathrm{CF}$ have alike molecular weight, they would be in different ionic forms in water due to protonation or deprotonation of their unlike functional groups at different pHs. Amphoteric TC molecules may mostly exist in a cationic form at $\mathrm{pH}<$ 3.3, resulting from the protonation of dimethyl ammonium group. At the $\mathrm{pH}$ ranging from 3.3 to 7.68 , it would present as a zwitterion due to the loss of a proton from the phenolic diketone moiety. At $\mathrm{pH}>7.68$, it mostly occurs as an anion when the tricarbonyl system and phenolic diketone moiety deprotonated (Kulshrestha et al. 2004, Liu et al. 2012). In comparison, the CF molecules having characteristic functional groups, including amino group and a carboxyl group, have $\mathrm{pKa}$ values of 7.3 and 2.5. It was thus assumed that $\mathrm{CF}$ molecules could become more negatively charged at lower solution $\mathrm{pH}$ than TC. Compared to TC, minor adsorption of $\mathrm{CF}$ was estimated as an importance of a greater Columbic repulsion force between $\mathrm{CF}$ and $\mathrm{BC} 600$. But, it was examined that the uptake of $\mathrm{CF}$ was higher than that of TC within the whole $\mathrm{pH}$ range. Moreover, there was same alteration on the adsorption presentation of $\mathrm{BC} 600$ for both $\mathrm{CF}$ and $\mathrm{TC}$ at $\mathrm{pH}$ $>7$ in which the Columbic repulsion between BC600 and CF/ TC molecules should be higher with the increasing $\mathrm{pH}$. So it could be determined that the Columbic interaction among cornstalk biochar and CF/TC molecules would somewhat affect the adsorption process. Meanwhile, the cornstalk biochar BC600 could work as -electron donors because it had a highly graphitized surface with relatively high -electron density. The TC and CF molecules were usually observed as -electron acceptors, prominent to a mechanism of electron-donor-acceptor (EDA) interaction involved in the improvement of adsorption onto BC600 (Teixidó et al. 2011, Zheng et al. 2013, Jing et al. 2014). Also, based on the results of $\mathrm{pH}$ effect, the zeta potential of biochar and species distribution of TC/CF under different solution $\mathrm{pH}$, the effect of Coulombic force between biochar and TC/ $\mathrm{CF}$ on the adsorption should be neglectable. The - electron-donor-acceptor (EDA) interaction between BC600 and $\mathrm{CF}$ was stronger than TC, yielding a comparatively higher adsorption capacity of CF on BC600 (Song et al. 2019). As the protonated and neutral species of TC and CF were more effective -electron acceptors, a slight reduction in TC and $\mathrm{CF}$ uptake was expected under alkaline conditions. This was consistent with results from the $\mathrm{pH}$ effect study. Thereby, it was deduced that the EDA interaction between BC600 and

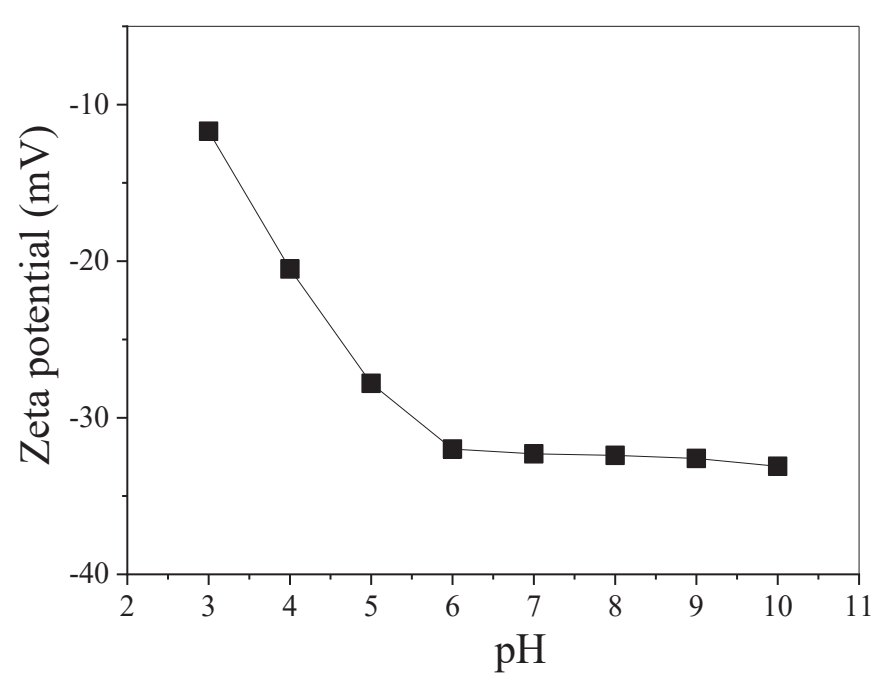

Fig. 6: Zeta potentials of cornstalk biochar BC600. Biochar dose $=200 \mathrm{mg} / \mathrm{L}$, ionic strength $0.01 \mathrm{M} \mathrm{NaNO}_{3}$, equilibrium time $48 \mathrm{~h}$. 
CF was stronger than that between BC600 and TC, yielding a comparatively higher uptake of CF on BC600.

\section{Adsorption Kinetics}

Adsorption kinetics of TC and $\mathrm{CF}$ onto the cornstalk biochar BC600 was investigated at $\mathrm{pH}$ 5.0, 7.0 and 9.0, respectively. Similar adsorption kinetics performances were observed for both the antibiotics. For simplicity, only the adsorption kinetics of TC and CF are presented in Figs. 7 and 8. Two kinetic models including pseudo-first-order and pseudo-second-order models were used to fit the kinetics data. The mathematical equations of the linear and non-linear models of the pseudo-first-order and the pseudo-second-order kinetics are those available in the literature (Lagergren 1898, Ho \& McKay 1999):

$$
\begin{gathered}
q_{t}=q_{e}\left(1-\mathrm{e}_{1}^{-k}{ }_{l}^{t}\right) \\
\ln \left(q_{e}-q_{t}\right)=\ln q_{e}-k_{I} \mathrm{t} \\
q_{t}=\frac{k_{2} q_{e}{ }^{2} t}{\left(1+k_{2} q_{e} t\right)}
\end{gathered}
$$

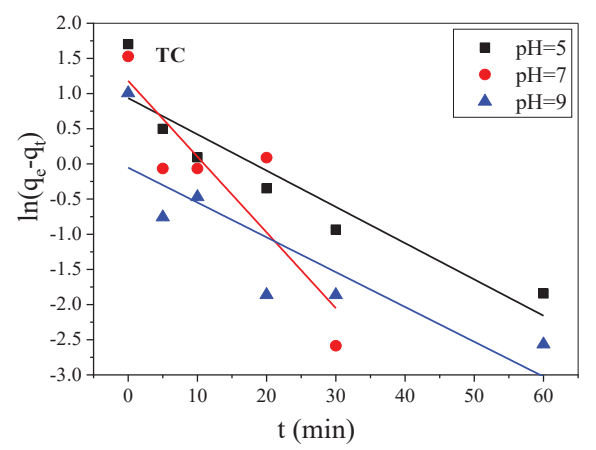

(a)

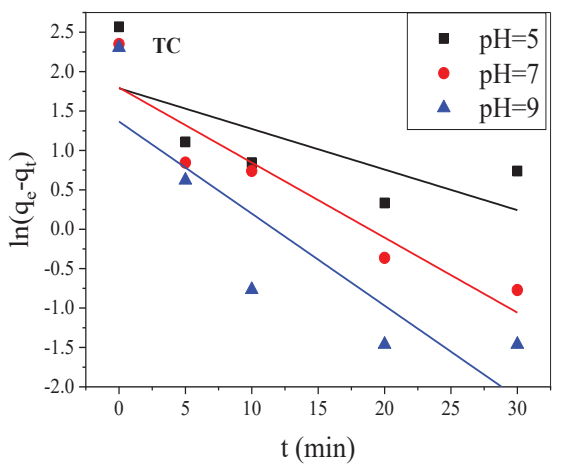

(c)

$$
\frac{t}{q_{t}}=\frac{1}{k_{2} q_{e}^{2}}+\frac{t}{q_{e}}
$$

Where, $q_{e}$ and $q_{t}$ are the adsorption capacities (mg/g) at equilibrium and at time $t$ (minutes), respectively; and $k_{1}\left(\mathrm{~min}^{-1}\right)$ and $k_{2}$ (g/mg.min) are the related adsorption rate constants for the pseudo-first-order and the pseudo-second-order model, respectively. Based on the correlation coefficients $\left(R^{2}\right)$, the experimental data can be better fitted by the pseudo-second-order kinetics model in both linear and nonlinear forms, indicating that the uptake of TC onto the cornstalk biochar might be a chemisorption process to some extent. According to the values of $k_{2}$, the adsorption of TC on cornstalk biochar BC600 at $\mathrm{pH} 7.0$ was relatively faster than that at $\mathrm{pH} 5$ and 9. This was beneficial for its practical application on the treatment of contaminated natural water (pH at around 6.8).

\section{Adsorption Isotherms}

Adsorption isotherms are the basis for analysing adsorption

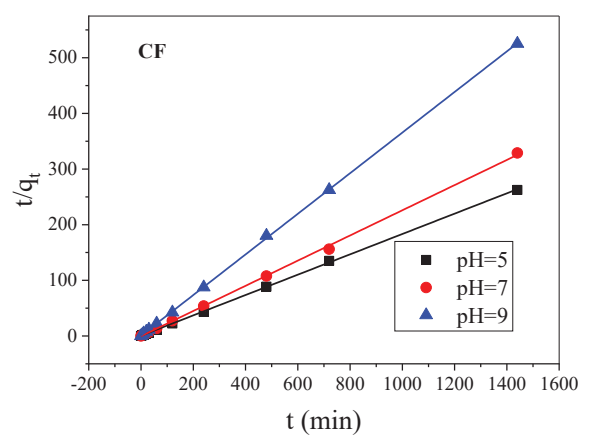

(b)

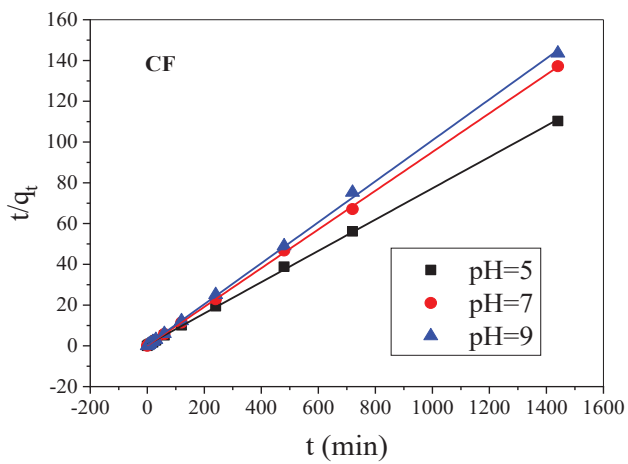

(d)

Fig. 7: Linear adsorption kinetics (a, c) and (b, d) for the pseudo-first-order and the pseudo-second-order models for TC and CF respectively. 


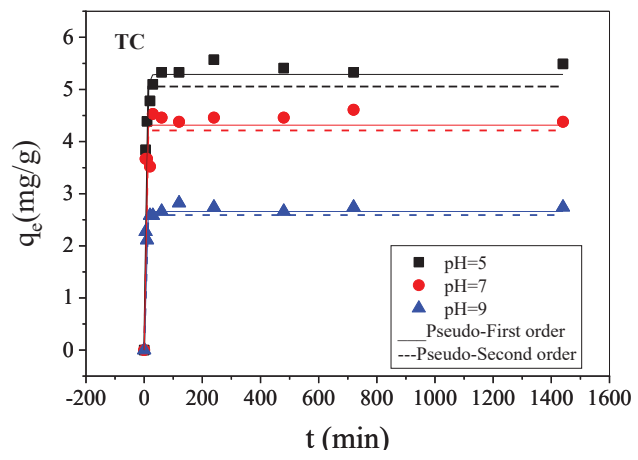

(a)

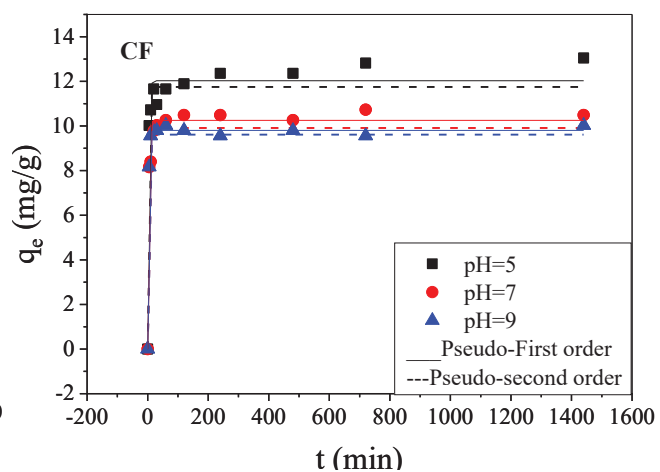

(b)

Fig. 8: Nonlinear pseudo-first-order and pseudo-second-order kinetic simulation for the adsorption of TC (a) and CF (b) respectively.

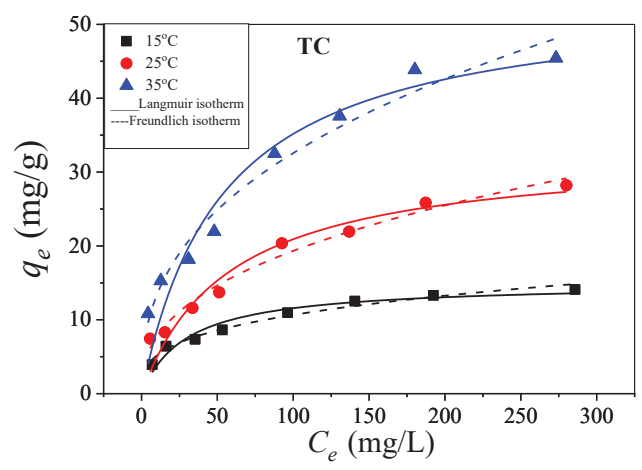

(a)

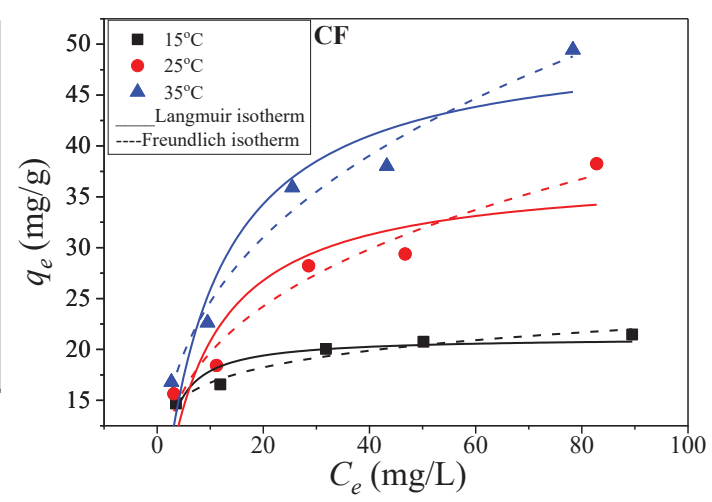

(b)

Fig. 9: Langmuir and Freundlich isotherm simulation for the adsorption of TC (a) and CF (b) respectively.

capacity and designing adsorption experiments. In this study, two classical isotherm models, Langmuir equation and Freundlich equation were used to fitting the experimental data.

The equations are as follows:

$$
\begin{aligned}
& \text { Langmuir Equation } q_{e}=\frac{q_{m} k_{L} C_{e}}{1+k_{L} C_{e_{1}}} \\
& \text { Freundlich Equation: } q_{e}=k_{F} C^{\frac{-}{n}}{ }_{e}
\end{aligned}
$$

Where, $q_{e}$ equilibrium adsorption amount $(\mathrm{mg} / \mathrm{g}) ; q_{m}$ is the maximum adsorption capacity $(\mathrm{mg} / \mathrm{g}) ; C_{e}$ equilibrium concentration of the adsorbate in the solution $(\mathrm{mg} / \mathrm{L}) ; k_{L}$ is Langmuir isotherm constant $(\mathrm{L} / \mathrm{mg})$, related to the energy of adsorption); $k_{F}$ is the Freundlich isotherm constant (related to the adsorption capacity and strength of the adsorbent); $n$ isothermal constants. The results of the adsorption isotherms of Langmuir and Freundlich models for the adsorption of TC and $\mathrm{CF}$ on cornstalk biochar are shown in Fig. 9.

From Table 1, we can see that the adsorption of TC on cornstalk biochar was more in line with Freundlich isotherm,

Table 1: Langmuir and Freundlich isotherm parameters for adsorption of TC on cornstalk biochar at different temperatures.

\begin{tabular}{|lllllll|}
\hline \multirow{2}{*}{ Temperature } & \multicolumn{2}{l}{ Langmuir isotherm } & \multicolumn{3}{l}{ Freundlich isotherm } \\
\cline { 2 - 6 } & $q_{m}(\mathrm{mg} / \mathrm{g})$ & $K_{L}(\mathrm{~L} / \mathrm{mg})$ & $R^{2}$ & $k_{F}$ & $R^{2}$ & 0.975 \\
$288 \mathrm{~K}$ & 14.98 & $3.376 \times 10^{-2}$ & 0.942 & 2.495 & 3.172 & 2.505 \\
$298 \mathrm{~K}$ & 32.94 & $1.737 \times 10^{-2}$ & 0.926 & 3.076 & 5.976 \\
$308 \mathrm{~K}$ & 53.9 & $1.877 \times 10^{-2}$ & 0.914 & 5.456 & 2.577 \\
\hline
\end{tabular}


and the correlation coefficient is above 0.96. However, it can be seen from Langmuir isotherm that as the temperature increases, $q_{m}$ increases, which is an endothermic reaction.

The thermodynamic function of the reaction is calculated using the following equations:

Gibbs equation: $G^{\circ}=\mathrm{RT} \ln \mathrm{K}$

Van't Hoff equation: $G^{\circ}=H^{\circ}-\mathrm{T} S^{\circ}$

Where: $G^{\circ}$ is the standard adsorption Gibbs free energy $(\mathrm{J} / \mathrm{mol}), S^{\circ}$ is the standard adsorption entropy change (J•mol$\left.1 \cdot \mathrm{K}^{-1}\right), H^{\circ}$ is the standard adsorption entropy change $(\mathrm{KJ} /$ $\mathrm{mol})$, and $\mathrm{R}$ is the gas molar constant $\left(8.314 \mathrm{~J} \bullet \mathrm{mol}-1 \cdot \mathrm{K}^{-1}\right)$, $\mathrm{T}$ is the thermodynamic temperature $(\mathrm{K})$, and $\mathrm{K}$ is the equilibrium adsorption constant. In the actual calculation of thermodynamic parameters, the following method was used. At different temperatures and different $q_{e}$, the corresponding $C_{e}$ was calculated according to the Freundlich isotherm equation at different temperatures, and the corresponding $\mathrm{K}$ value was obtained. By using $q_{e}$ as the abscissa and $\ln \left(q_{e} /\right.$ $C_{e}$ ) as the ordinate under different temperatures and different $q_{e}$, plot Fig.10(a), and then the corresponding $\mathrm{K}$ value was obtained, and $G^{\circ}$ to map T to Fig.10 (b) was used to obtain a straight line from the slope and intercept of the line $H^{\circ}$ and $S^{\circ}$ respectively, as given in Table 2 .

It can be seen from Table 2 that the process of adsorbing TC by cornstalk biochar is spontaneous and an endothermic reaction. The positive value of $H^{\circ}$ indicates that the process absorbs heat, and the elevated temperature favours the occurrence of adsorption reaction, which is consistent with the experimental theoretical maximum equilibrium adsorption amount. $S^{\circ}$ is a positive value, indicating that the adsorption process is an entropy increase reaction. $G^{\circ}$ is a negative value, indicating that the reaction is a spontaneous reaction process, and $G^{\circ}$ decreases with increasing temperature, indicating that the higher the temperature, the more favourable the adsorption process of TC adsorption by cornstalk biochar.

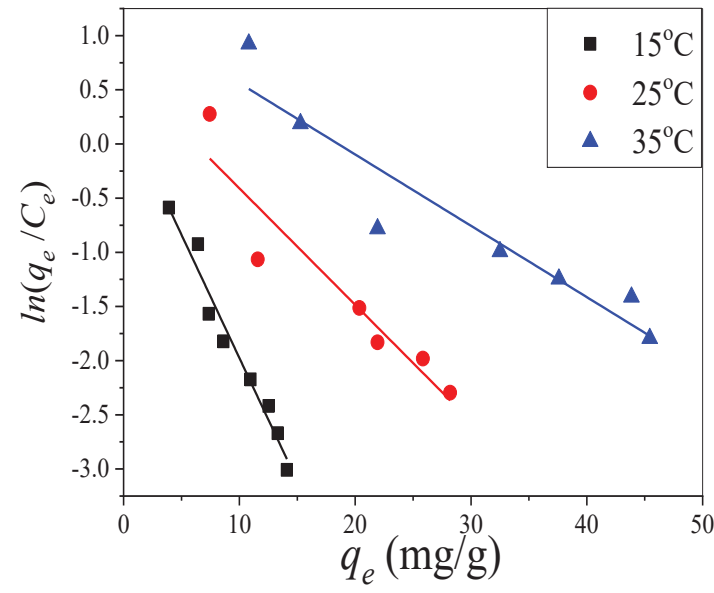

(a)

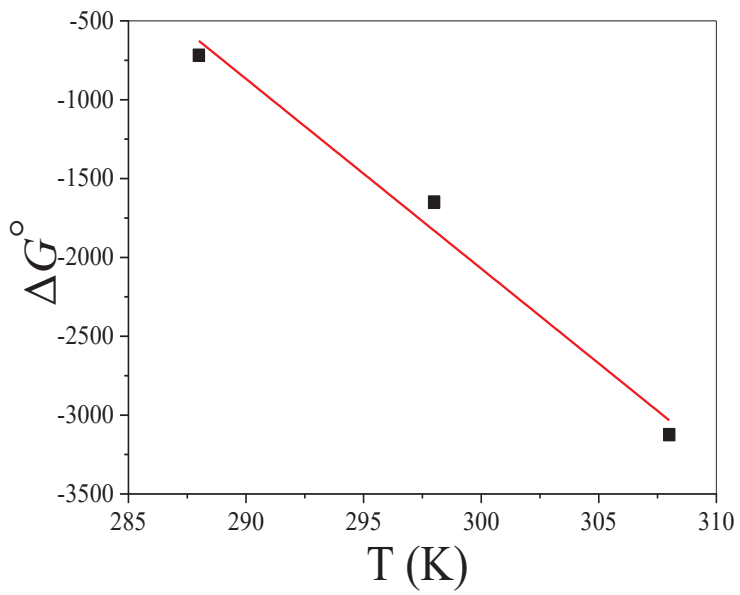

(b)

Fig. 10: Thermodynamic parameters $(\mathrm{a}, \mathrm{b})$ for TC adsorption on cornstalk biochar.

Table 2: Thermodynamic parameters at different reaction temperatures.

\begin{tabular}{|lllll|}
\hline Temperature & $\ln \mathrm{K}$ & $G^{\circ}(\mathrm{kJ} / \mathrm{mol})$ & $H^{\circ}(\mathrm{kJ} / \mathrm{mol})$ & $S^{\circ}\left(\mathrm{J} \cdot \mathrm{mol}^{-1} \cdot \mathrm{K}^{-1}\right)$ \\
\hline $288 \mathrm{~K}$ & 0.2998 & -0.718 & 34.02 & 120.30 \\
$298 \mathrm{~K}$ & 0.6655 & -1.649 & 34.02 & 120.30 \\
$308 \mathrm{~K}$ & 1.220 & -3.124 & 34.02 & 120.30 \\
\hline
\end{tabular}

Table 3: Langmuir and Freundlich isotherm parameters of CF adsorption on cornstalk biochar at different temperatures.

\begin{tabular}{|lllllll|}
\hline \multirow{2}{*}{ Temperature } & \multicolumn{2}{l}{ Langmuir isotherm } & \multicolumn{5}{l}{ Freundlich isotherm } \\
\cline { 2 - 6 } & $q_{m}(\mathrm{mg} / \mathrm{g})$ & $K_{L}(\mathrm{~L} / \mathrm{mg})$ & $R^{2}$ & $k_{F}$ & $n$ & $R^{2}$ \\
\hline $288 \mathrm{~K}$ & 21.20 & 0.538 & 0.830 & 12.552 & 8.021 & 3.953 \\
$298 \mathrm{~K}$ & 37.56 & 0.124 & 0.752 & 9.873 & 11.488 & 3.015 \\
$308 \mathrm{~K}$ & 50.51 & 0.103 & 0.861 & 0.947 & 0.974 \\
\hline
\end{tabular}


For $\mathrm{CF}$ the thermodynamic function of the reaction was calculated using the equations (9) and (10). From Table 3, we can see that the adsorption of CF on corn straw biochar is more in line with Freundlich isotherm, and the correlation coefficient is above 0.94 . However, it can be seen from Langmuir isotherm that as the temperature increases, $q_{m}$ increases, which is an endothermic reaction.

The positive value of $H^{\circ}$ indicates that adsorption of $\mathrm{CF}$ by cornstalk biochar is a spontaneous process and an endothermic reaction that absorbs heat, and the elevated temperature favours the occurrence of adsorption reaction, which is consistent with the experimental theoretical maximum equilibrium adsorption amount. $S^{\circ}$ is a positive value, indicating that the adsorption process is an entropy increase reaction. $G^{\circ}$ is a negative value, indicating that the reaction is a spontaneous reaction process, and $G^{\circ}$ decreases with increasing temperature, indicating that the higher the temperature, the more favourable the adsorption process of $\mathrm{CF}$ on cornstalk biochar adsorption.

\section{Effect of Natural Organic Matter on the Adsorption of TC and CF}

We have checked the effect of the amount of natural material quantity on the adsorption of TC and CF as give in the graphs (a) and (b) of Fig. 11. The adsorption of TC at $20 \mathrm{mg} / \mathrm{L}$ was just $20.21 \mathrm{mg} / \mathrm{g}$, while in the case of $\mathrm{CF}$ at $20 \mathrm{mg} / \mathrm{L}$ was increased to a value of $93.00 \mathrm{mg} / \mathrm{g}$. Hence, we can conclude without any doubt that $\mathrm{CF}$ has a higher adsorption capacity than TC on the cornstalk biochar BC600.

\section{CONCLUSION}

A simple pyrolysis process was used for the preparation of cornstalk biochar which can be used for relative adsorption of two antibiotics tetracycline (TC) and cefradine (CF). The dens morphology of geared up cornstalk biochar pyrolyzed at $600^{\circ} \mathrm{C}$ (BC600) had a more condensed configuration, which is responsible to make biochar developed greater hydrophobic and carbon-rich with increasing pyrolytic temperature. The uptake of TC and CF decreased step by step with higher $\mathrm{pH}$ whilst the uptake of CF used to be certainly greater than that of TC at a low adsorbate concentration. Based on the effects of $\mathrm{pH}$ effect, the zeta potential of biochar and distribution kinds of TC/CF beneath exclusive solution $\mathrm{pH}$, impact of Coulombic force between biochar and TC/CF on the adsorption have to be neglectable. The - electron-donor-acceptor (EDA) interaction between CF and BC600 used to be higher than TC, and resilient a relatively greater adsorption potential of $\mathrm{CF}$ on BC600. Kinetics statistics can be fitted out higher by means of the use of the pseudo-second-order kinetic model, indicating a possible chemisorption process to some extent. Isotherms learn about advised that both ground adsorption and partitioning contributed to the uptake of TC and CF onto BC600.

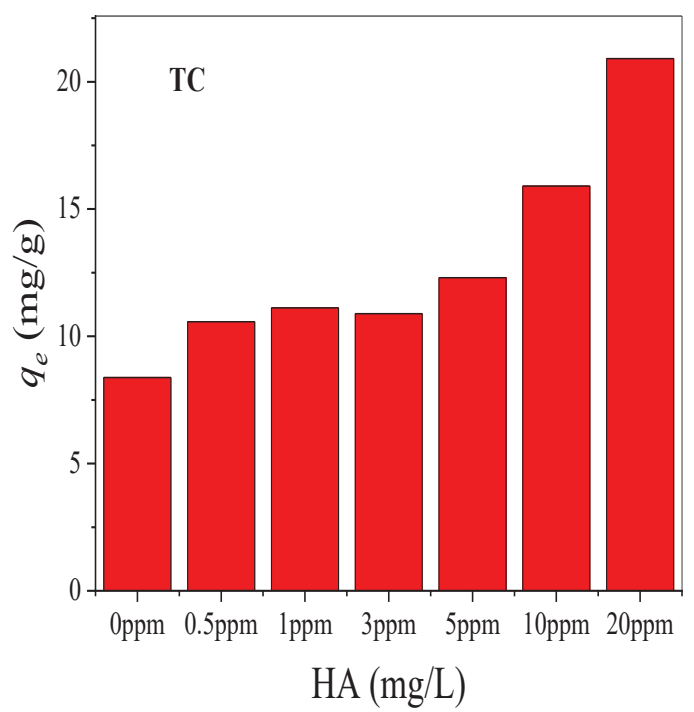

(a)

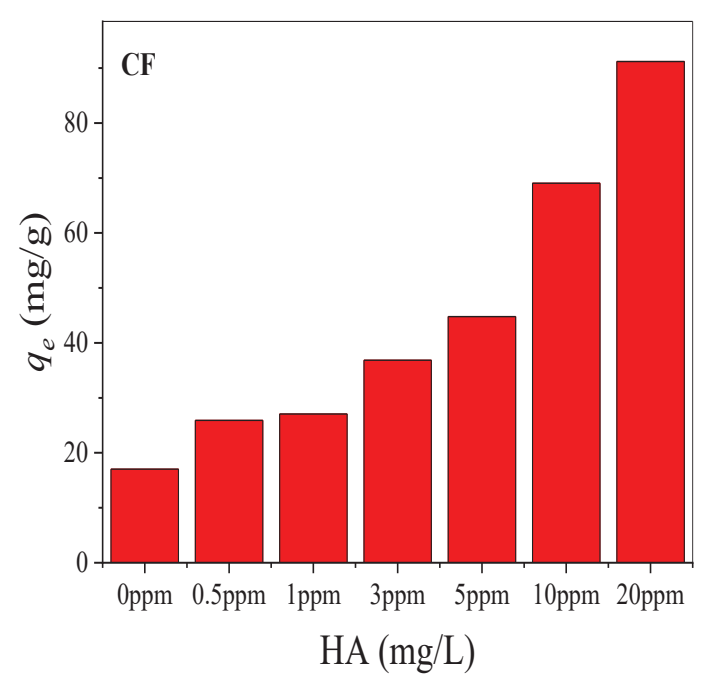

(b)

Fig. 11: Effect of humic acid (HA) on the adsorption of TC (a) and CF (b). 


\section{ACKNOWLEDGEMENT}

The authors thank for the financial support from National Natural Science Foundation of China (No. 51509088), Henan province, University Scientific and Technological Innovation Team (No. 18IRTSTHN009), and Henan Key Laboratory of Water Environment Simulation and Treatment (No. 2017016).

\section{ABBREVIATIONS}

TC - Tetracycline

$\mathrm{CF}$ - Cefradine

EDA - Electron-donor-acceptor

PPCPs - Pharmaceutical and personal care products

DI water - Deionized water

Biochar - BC

SEM - Scanning electron microscope

EDX - Energy dispersive X-ray

BET - Brunauer, Emmett and Teller

FTIR - Fourier transform infrared spectroscopy

$R^{2}$ - Correlation coefficients

\section{REFERENCES}

Ahmad, M., Rajapaksha, A. U., Lim, J. E., Zhang, M., Bolan, N., Mohan, D. and Ok, Y. S. 2014. Biochar as a sorbent for contaminant management in soil and water: A review. Chemosphere, 99: 19-33.

Ahmadzadeh, S., Rezayi, M., Karimi-Maleh, H. and Alias, Y. 2015. Conductometric measurements of complexation study between 4-Isopropylcalix[4] arene and $\mathrm{Cr}^{3+}$ cation in THF-DMSO binary solvents. Measurement: Journal of the International Measurement Confederation, 70: 214-224.

Al-Wabel, M. I., Al-Omran, A., El-Naggar, A. H., Nadeem, M. and Usman, A. R. A. 2013. Pyrolysis temperature induced changes in characteristics and chemical composition of biochar produced from Conocarpus wastes. Bioresource Technology, 131: 374-379.

Ali, I., Asim, M. and Khan, T. A. 2012. Low cost adsorbents for the removal of organic pollutants from wastewater. Journal of Environmental Management, 113: 170-183.

Avilez, H.V.R. 2012. Remoción de Cianuro en Relaves Auríferos Utilizando Biochar Producido a Partir de Tallos de Gliricida Sepium., Vol. 66.

Bai, Y., Meng, W., Xu, J., Zhang, Y. and Guo, C. 2014. Occurrence, distribution and bioaccumulation of antibiotics in the Liao River Basin in China. Environmental Sciences: Processes and Impacts, 16(3): 586-593.

Carvalho, W. S., Martins, D. F., Gomes, F. R., Leite, I. R., Gustavo da Silva, L., Ruggiero, R. and Richter, E.M. 2011. Phosphate adsorption on chemically modified sugarcane bagasse fibres. Biomass and Bioenergy, 35(9): 3913-3919.

Chen, B. and Chen, Z. 2009. Sorption of naphthalene and 1-naphthol by biochars of orange peels with different pyrolytic temperatures. Chemosphere, 76(1): 127-133.

Chen, Y. di, Ho, S. H., Wang, D., Wei, Z. Su, Chang, J. S. and Ren, N. qi. (2018). Lead removal by magnetic biochar derived from persulfate-ZVI treated sludge together with one-pot pyrolysis. Bioresource Technology, 247: 463-470.

Chen, X., Chen, G., Chen, L., Chen, Y., Lehmann, J., McBride, M. B. and Hay, A. G. 2011. Adsorption of copper and zinc by biochars produced from pyrolysis of hardwood and corn straw in aqueous solution. Bioresource Technology, 102(19): 8877-8884.

Chun, Y., Sheng, G., Chiou, G. T. and Xing, B. 2004. Compositions and sorptive properties of crop residue-derived chars. Environmental Science and Technology, 38(17): 4649-4655.

Cornelissen, G. and Gustafsson, Ö. 2005. Importance of unburned coal carbon, black carbon, and amorphous organic carbon to phenanthrene sorption in sediments. Environmental Science and Technology, 39(3): 764-769.

Da-li, S., Sheng-peng, H. and Xiu-bin, W. 2018. Nutrient resource quantity of crop straw and its potential of substituting. Journal of Plant Nutrition and Fertilizers, 24(01): 1-21.

Figueroa, R.A., Leonard, A. and Mackay, A.A. 2004. Modeling tetracycline antibiotic sorption to clays. Environmental Science and Technology, 38(2): 476-483.

Gao, L., Shi, Y., Li, W., Liu, J. and Cai, Y. 2012. Occurrence, distribution and bioaccumulation of antibiotics in the Haihe River in China. Journal of Environmental Monitoring, 14(4): 1248-1255.

Ge, J. and Qu, J. 2003. Degradation of azo dye acid red B on manganese dioxide in the absence and presence of ultrasonic irradiation. Journal of Hazardous Materials, 100(1-3): 197-207.

Ho, Y. S. and McKay, G. 1999. Pseudo-second order model for sorption processes. Process Biochemistry, 34(5): 451-465.

Jing, X.R., Wang, Y.Y., Liu, W.J., Wang, Y. K. and Jiang, H. 2014. Enhanced adsorption performance of tetracycline in aqueous solutions by methanol-modified biochar. Chemical Engineering Journal, 248: 168-174.

Kim, H. Y., Jeon, J., Hollender, J., Yu, S. and Kim, S. D. 2014. Aqueous and dietary bioaccumulation of antibiotic tetracycline in D. magna and its multigenerational transfer. Journal of Hazardous Materials, 279: 428-435.

Kim, S., Eichhorn, P., Jensen, J. N., Weber, A.S. and Aga, D. S. 2005. Removal of antibiotics in wastewater: Effect of hydraulic and solid retention times on the fate of tetracycline in the activated sludge process. Environmental Science and Technology, 39(15): 5816-5823.

Kulshrestha, P., Giese, R.F. and Aga, D.S. 2004. Investigating the molecular interactions of oxytetracycline in clay and organic matter: Insights on factors affecting its mobility in soil. Environmental Science and Technology, 38(15): 4097-4105.

Lagergren, S. 1898. Zurtheorie der sogenannten adsorption gelösterstoffe. Kungliga Svenska Vetenskapsakademiens. Handlinga, 24: 1-39.

Lee, J. W., Hawkins, B., Day, D. M. and Reicosky, D. C. 2010. Sustainability: The capacity of smokeless biomass pyrolysis for energy production, global carbon capture and sequestration. Energy and Environmental Science, 3(11): 1695-1705.

Lehmann, J. 2007. A handful of carbon. Nature, 447(7141): 143-144.

Li, W. H., Yue, Q. Y., Gao, B. Y., Ma, Z. H., Li, Y. J. and Zhao, H. X. 2011. Preparation and utilization of sludge-based activated carbon for the adsorption of dyes from aqueous solutions. Chemical Engineering Journal, 171(1): 320-327.

Liu, H., Yang, Y., Kang, J., Fan, M. and Qu, J. 2012. Removal of tetracycline from water by Fe-Mn binary oxide. Journal of Environmental Sciences, 24(2): 242-247.

Luo, J., Im, J. H., Mayer, M. T., Schreier, M., Nazeeruddin, M. K., Park, N. G. and Grätzel, M. 2014. Water photolysis at $12.3 \%$ efficiency via perovskite photovoltaics and Earth-abundant catalysts. Science, 345(6204): 1593-1596.

Monsalvo, V. M., Mohedano, A. F. and Rodriguez, J. J. 2011. Activated carbons from sewage sludge. Application to aqueous-phase adsorption of 4-chlorophenol. Desalination, 277(1-3): 377-382.

Peng, X., Liu, X., Zhou, Y., Peng, B., Tang, L., Luo, L. and Zeng, G. 2017. New insights into the activity of a biochar supported nanoscale zerovalent iron composite and nanoscale zero valent iron under anaerobic or aerobic conditions. RSC Advances, 7(15): 8755-8761. 
Polubesova, T., Zadaka, D., Groisman, L. and Nir, S. 2006. Water remediation by micelle-clay system: Case study for tetracycline and sulfonamide antibiotics. Water Research, 40(12): 2369-2374.

$\mathrm{Qu}$, J. 2008. Research progress of novel adsorption processes in water purification: A review. Journal of Environmental Sciences, 20(1): 1-13.

Rokhina, E. V., Makarova, K., Lahtinen, M., Golovina, E. A., Van As, H. and Virkutyte, J. 2013. Ultrasound-assisted $\mathrm{MnO}_{2}$ catalyzed homolysis of peracetic acid for phenol degradation: The assessment of process chemistry and kinetics. Chemical Engineering Journal, 221: 476-486.

Song, G., Guo, Y., Li, G., Zhao, W. and Yu, Y. 2019. Comparison for adsorption of tetracycline and cefradine using biochar derived from seaweed Sargassum sp. Desalination and Water Treatment, 160: 316-324.

Sun, Y., Gao, B., Yao, Y., Fang, J., Zhang, M., Zhou, Y. and Yang, L. 2014. Effects of feedstock type, production method, and pyrolysis temperature on biochar and hydrochar properties. Chemical Engineering Journal, 240: 574-578.

Teixidó, M., Pignatello, J.J., Beltrán, J.L., Granados, M. and Peccia, J. 2011. Speciation of the ionizable antibiotic sulfamethazine on black carbon (Biochar). Environmental Science and Technology, 45(23): 10020-10027.

Wang, S., Zhou, Y., Gao, B., Wang, X., Yin, X., Feng, K. and Wang, J. 2017. The sorptive and reductive capacities of biochar supported nanoscale zero-valent iron (nZVI) in relation to its crystallite size. Chemosphere,
186: 495-500.

Yang, F., Sun, L., Xie, W., Jiang, Q., Gao, Y., Zhang, W. and Zhang, Y. 2017. Nitrogen-functionalization biochars derived from wheat straws via molten salt synthesis: An efficient adsorbent for atrazine removal. Science of the Total Environment, 607-608: 1391-1399.

Yang, F., Sun, L., Zhang, W. and Zhang, Y. 2017. One-pot synthesis of porous carbon foam derived from corn straw: atrazine adsorption equilibrium and kinetics. Environmental Science: Nano, 4(3): 625-635.

Yang, F., Zhang, W., Li, J., Wang, S., Tao, Y., Wang, Y. and Zhang, Y. 2017. The enhancement of atrazine sorption and microbial transformation in biochars amended black soils. Chemosphere, 189: 507-516.

Yao, Y., Gao, B., Fang, J., Zhang, M., Chen, H., Zhou, Y. and Yang, L. 2014. Characterization and environmental applications of clay-biochar composites. Chemical Engineering Journal, 242: 136-143.

Zheng, H., Wang, Z., Zhao, J., Herbert, S. and Xing, B. 2013. Sorption of antibiotic sulfamethoxazole varies with biochars produced at different temperatures. Environmental Pollution, 181: 60-67.

Zhou, Y., Zhang, L. and Cheng, Z. 2015. Removal of organic pollutants from aqueous solution using agricultural wastes: A review. Journal of Molecular Liquids, 212: 739-762.

Zhu, X., Liu, Y., Zhou, C., Luo, G., Zhang, S. and Chen, J. 2014. A novel porous carbon derived from hydrothermal carbon for efficient adsorption of tetracycline. Carbon, 77: 627-636. 